\title{
PENGARUH WORK LIFE BALANCE TERHADAP KINERJA KARYAWAN MELALUI KOMITMEN ORGANISASI PADA KARYAWAN PT. BHINNEKA LIFE INDONESIA CABANG SURABAYA
}

\author{
Choirul Adam Ardiansyah \\ Universitas Negeri Surabaya \\ choirulardiansyah@mhs.unesa.ac.id \\ Jun Surjanti \\ Universitas Negeri Surabaya \\ junsurjanti@unesa.ac.id
}

Abstract

\begin{abstract}
The purpose of this study is to analyze the relationship between work-life balance and employee performance through an organizational commitment to the employees of PT. Bhinneka Life Indonesia Surabaya branch. This type of research is quantitative research. The study used a saturated sample technique with a total of 50 permanent employees at PT. Bhinneka Life Indonesia Surabaya branch. From the results of statistical analysis, this study uses Partial Least Square (PLS) and is assisted with smartPLS 3.0 software. This research shows the results of work-life balance has no relationship with employee performance. Work-life balance has a positive effect on commitment. While commitment has a relationship with performance. And the commitment variables can mediate the effect between work-life balance on employee performance. This study shows the results of work-life balance have a smaller direct relationship than an indirect effect on the performance of employee. The implications are based on results of research applied to companies that superiors can provide training to employees on the importance of managing the time between life at work and life outside of work such as life at home. Also, the employees can pay attention to their comfort while working or in receiving bonuses when the targets set by the company have been achieved. Supervisors can also provide other training to the employees to improve the quality of their work.
\end{abstract}

Keywords: employee performance; organizational commitment; work life balance.

\section{PENDAHULUAN}

Perusahaan Asuransi harus memiliki legalitas yang jelas dalam menjalankan bisnisnya sebagai upaya menjaga loyalitas dan menumbuhkan kepercayaan pelanggan kepada perusahaan (Peraturan Otoritas Jasa Keuangan Nomor 67 /POJK.05/2016). Dalam upaya menghadapi persaingan dengan perusahaan asuransi lain yang ada di Indonesia, dari hasil observasi di PT. Bhinneka Life Indonesia cabang Surabaya, perusahaan dapat memanfaatkan potensi karyawan yang ada di perusahaan dan karyawan yang siap memberikan yang terbaik untuk perkembangan perusahaan, yang dimaksud adalah kinerja dari keryawan. Hal ini menjadi bukti bahwa kinerja dari karyawan merupakan salah satu aspek yang berperan besar dalam menentukan tujuan dari kemajuan perusahaan.

Dari data perusahaan diperoleh hasil pencapaian kinerja karyawan PT. Bhinneka Life Indonesia cabang Surabaya dijelaskan bahwa pada tahun 2017 jumlah karyawan yang bekerja di PT. Bhinneka Life Indonesia cabang Surabaya ada sebanyak 15 orang dengan kinerja yang mereka hasilkan sebanyak 550 pelanggan asuransi baru di Bhinneka Life Indonesia. Sedangkan pada 2018 karyawan yang bekerja di PT. Bhinneka Life Indonesia cabang Surabaya mengalami kenaikan sebanyak 30 orang dengan kinerja yang mereka hasilkan pada tahun tersebut sebanyak 1.080 pelanggan baru untuk asuransi Bhinneka Life Indonesia. Tahun 2019, karyawan PT. Bhinneka Life Indonesia cabang Surabaya sebanyak 50 orang dengan kinerja yang dihasilkan pada tahun tersebut sebanyak 1.800 pelanggan baru yang untuk asuransi Bhinneka Life Indonesia.

Menurut Metin \& Asli (2018), kinerja merupakan bentuk realisasi dari pencapaian visi misi perusahaan dan bisa menjadi alat ukur untuk setiap individu, kelompok, maupun unit kerja agar bisa mencapai atau bahkan melebihi produksi yang sudah ditetapkan. Meningkatnya kinerja karyawan 
Choirul Adam Ardiansyah \& Jun Surjanti. Pengaruh Work Life Balance terhadap Kinerja Karyawan melalui Komitmen Organisasi pada Karyawan PT. Bhinneka Life Indonesia Cabang Surabaya

dapat dilakukan dengan menerapkan kebijakan yang dapat membuat karyawan rilek dalam bekerja dan tidak tertekan dengan beban dari perusahaan berupa tugas-tugas yang dapat menyita waktu mereka untuk lebih lama di kantor.

PT. Bhinneka Life Indonesia memiliki karyawan dengan sifat yang beranekaragam, mempunyai perilaku yang bervariasi, serta adat atau kepercayaan yang berbeda. Dalam hal ini mengakibatkan para karyawan memberikan pandangan berbeda tentang situasi kerja saat ini yang memberikan diferensiasi terhadap variasi kerja karyawan di beberapa organisasi. Hal ini mendorong PT. Bhinneka Life Indonesia merubah pekerjaan para karyawan yang biasanya di kantor mulai pagi sampai sore hari kini mereka hanya perlu ke kantor ketika akan absen datang dan pulang saja, selebihnya mereka bisa keluar kantor untuk mencari calon konsumen baru.

Menurut Weerakkod \& Mendis (2017), work life balanced adalah usaha yang dilakukan oleh perusahaan untuk menyesuaikan pola kerja dari karyawan agar dapat menjalankan urusan tanggung jawab mereka di rumah dengan pekerjaan yang mereka lakukan di perusahaan agar bisa jalan seimbang. Menurut Andini \& Surjanti (2017), work life balance ialah bentuk kebijakan dari perusahaan agar karyawan bebas mengatur waktu antara di tempat kerja mereka dengan waktu untuk keperluan lain di luar perusahaan seperti urusan keluarga, hobi, seni, studi, dll.

Hasil penelitian Obiageli, Uzochukwu, \& Ngozi (2015) telah membuktikan bahwa work life balanced berkorelasi signifikan positif terhadap kinerja karyawan bank komersial yang terdapat pada negara bagian Lagos. Menurut Weerakkod \& Mendis (2017), Work Life Balanced memiliki korelasi positif dengan Kinerja Karyawan level eksekutif pada PT industry telekomunikasi di Sri Lanka. Menurut Kithae \& Keino (2016), work life balanced memiliki korelasi negatif terhadap kinerja para karyawan senior di Telkom Kenya's Orange dan Kantor Pusat Essar Yu Kenya di Nairobi.

Hal lain yang dapat mendorong terjadinya peningkatan kinerja karyawan salah satunya ialah komitmen organisasi. Loyalitas karyawan merupakan salah satu bentuk dari komitmen organisasi (Nugraha, Toni, 2020). Menurut Arifin, Rivai, \& Sodikin (2018), komitmen organisasi ialah bentuk sikap yang ditunjukkan karyawan dengan menerima visi misi yang ada di organisasi dan nilai yang terkandung di perusahaan, serta ada keinginan sendiri dari karyawan untuk mengembangkan organisasi ke arah lebih baik sehingga para karyawan merasakan kedekatan emosional dengan perusahaan yang dibuktikan dekatnya para karyawan dengan rekan kerja serta atasan mereka dan karyawan merasa masih dibutuhkan untuk perkembangan organisasi, hal ini yang membuat karyawan memilih untuk tetap bekerja di tempat mereka bekerja sekarang.

Hasil penelitian Berk \& Gundogmus (2018) telah membuktikan bahwa work life balanced berdampak positif ke komitmen karyawan akuntan terhadap organisasi di Istanbul, Turki. Hasil penelitian Duarte (2017) telah membuktikan bahwa work life balanced dan komitmen guru di universitas Gujrat memiliki hubungan signifikan. Hasil penelitian Azeem \& Akhtar (2014) telah membuktikan bahwa work life balanced dan komitmen pada pelayanan kesehatan di organisasi memiliki dampak positif. Menurut Rene \& Wahyuni (2018), work life balanced tidak memiliki hubungan positif dengan komitmen karyawan di perusahaan asuransi Jakarta.

Menurut Arifin et al. (2018), komitmen organisasi ialah sikap yang ditunjukkan oleh karyawan dengan menerima visi misi perusahaan dan nilai yang terkandung di perusahaan untuk kepentingan perkembangan organisasi tempat karyawan bekerja. Pengaruh yang di berikan perusahaan terhadap karyawan dan menumbuhkan rasa puas membuat para karyawan lebih senang ketika bekerja pada perusahaan tersebut dibandingkan dengan individu yang mendapat perlakuan yang tidak enak dalam bekerja.

Menurut Martini, Rahyuda, Sintaasih, \& Piartrini (2018), komitmen efektif, komitmen normative, dan komitmen berkelanjutan berdampak positif terhadap kinerja karyawan tenun di Kabupaten Klungkung. Hasil penelitian Cesário \& Chambel (2017) telah membuktikan adanya hubungan signifikan antara kinerja karyawan dan komitmen efektif, komitmen normative dan keterlibatan kerja. 
Hasil penelitian Arifin et al. (2018) telah membuktikan adanya dampak yang ditimbulkan antara komitmen karyawan terhadap organisasi dengan kinerja karyawan di PT. Parsariran. Hasil penelitian Koskei, Kimutai, \& Bogonko (2018) telah membuktikan tidak adanya dampak yang ditimbulkan antara komitmen karyawan pada organisasi dengan kinerja kerja dari karyawan di university of Eastren Africa, Baraton.

Dilihat dari fenomena di perusahaan PT. Bhinneka Life Indonesia Cabang Surabaya dan dari penjelasan di atas. Ada permasalahan yang terjadi, diantaranya kurang berkomitmennya karyawan secara penuh terhadap perusahaan karena pekerjaan mereka yang bersifat fleksibel. Hal ini terbukti dengan tidak teraturnya urusan kantor karena terdapat banyak urusan lain yang didahulukan oleh para karyawan daripada urusan kantor. Meskipun untuk sekarang tidak memiliki dampak yang begitu berarti pada kinerja karyawan. Dalam hal ini tidak menutup kemungkinan akan menimbulkan dampak pada kinerja karyawan di kemudian hari.

Tujuan penelitian ini adalah untuk mengetahui apakah karyawan PT. Bhinneka Life Indonesia cabang Surabaya dapat membagi waktu mereka antara di tempat kerja dan waktu kehidupan pribadi mereka dengan secara tepat dan didukung oleh komitmen karyawan yang tinggi untuk menaikkan kinerja karyawan.

\section{KAJIAN PUSTAKA DAN PENGEMBANGAN HIPOTESIS}

\section{Work Life Balance}

Menurut Berk \& Gundogmus (2018) mendefinisikan work life balance sebagai dukungan organisasi untuk aspek kehidupan pribadi karyawan seperti pekerjaan yang mempunyai jam fleksibel, perawatan dependen dan cuti keluarga/ pribadi. Menurut Mendis \& Weerakkody (2017), work life balance merupakan pola kerja yang memungkinkan karyawan menggabungkan antara tanggung jawab karyawan di tempat kerja dengan tanggung jawab karyawan yang lain seperti merawat anak atau saudara yang sudah lanjut usia. Menurut Obiageli et al. (2015), work life balanced merupakan konflik peran yang terjadi ketika peran seseorang sebagai karyawan tidak sesuai dengan bidang lain seperti mejadi pasangan, orang tua, atau kegiatam keagamaan, kegiatan rekreasi, dll. Sedangkan menurut Wambui, Cherotich, Emily, \& Dave (2017), menyatakan work life balanced bertujuan untuk membimbing karyawan untuk mencapai keseimbangan antara pekerjaan mereka di tempat kerja dan kehidupan pribadi mereka.

Dari kutipan beberapa penelitian menyatakan bahwa work life balanced ialah bentuk kebijakan dari perusahaan agar karyawan bebas mengatur waktu antara di tempat kerja mereka dengan waktu untuk keperlAan lain di luar perusahaan seperti urusan keluarga, hobi, seni, studi, dll (Andini \& Surjanti, 2017). Dengan work life balance, karyawan tidak akan pernah mengabaikan semua aspek kehidupan kerja, pribadi, keluarga, spiritual, dan sosial (Djajendra, 2013).

Penelitian ini menggunakan indikator dari Langford (2009) karena kasus keseimbangan kehidupan kerja yang terjadi di perusahaan meliputi hal-hal yang telah disebutkan oleh penelitian sebelumnya. Adapun isi dari indikator tersebut adalah keseimbangan waktu pekerjaan dan keperluan lain, bertanggung jawab penuh kepada keluarga ataupun perusahaan, kehidupan sosial yang baik di luar perusahaan, serta terbatasnya waktu untuk hobi.

\section{Komitmen Organisasi}

Manurut Gulbahar, Ch., Kundi, Qureshi, \& Akhtar (2014) mengatakan komitmen organisasi ialah perasaan karyawan tentang pekerjaan mereka, identifikasi organisasi dan sejauh mana seorang karyawan mengalami "rasa kesatuan" dengan organisasi mereka. Menurut Metin \& Asli (2018), komitmen organisasi merupakan konsep penting karena memengaruhi komitmen pada karyawan, organisasi, dan masyarakat secara keseluruhan. Cesário \& Chambel (2017) mengatakan bahwa komitmen organisasi ialah sebuah keterikan psikologi yang terjadi antara karyawan perusahaan dengan organisasinya. Menurut Arifin et al. (2018), yang menyatakan bahwa komitmen organisasi 
Choirul Adam Ardiansyah \& Jun Surjanti. Pengaruh Work Life Balance terhadap Kinerja Karyawan melalui Komitmen Organisasi pada Karyawan PT. Bhinneka Life Indonesia Cabang Surabaya

ialah sikap yang ditunjukkan oleh karyawan dengan menerima visi misi perusahaan dan nilai yang terkandung di perusahaan untuk kepentingan perkembangan organisasi tempat karyawan bekerja.

Dari penjelasan kutipan penelitian di atas, komitmen organisasi ialah suatu sikap atau tingkah laku dari seseorang terhadap organiasasi berupa loyalitas serta tercapainya visi, misi dan juga tujuan organisasi (Ilham, Mughnifar, 2020). Komitmen di perusahaan sangat dibutuhkan untuk meningkatkan pekerjaan karyawan di perusahaan sehingga produktivitas karyawan dapat meningkat dan tujuan perusahaan tercapai (Sari, Usnawati Indria, 2015).

Penelitian ini menggunakan indikator dari Buhali \& Margaretha (2013) karena indikator yang disebutkan sudah mencakup atau menggambarkan kondisi di perusahaan. Adapun isi dari indikator tersebut yaitu keterikatan emosional karyawan terhadap organisasi (komitmen afektif), kerugian yang diterima karyawan jika mereka keluar dari organisasi (komitmen berkelanjutan), dan keputusan dari karyawan untuk tetap tinggal dalam organisasi adalah keputusan yang benar.

\section{Kinerja Karyawan}

Mangkunegara (2009) menjelaskan kinerja karyawan juga bisa diartikan sebagai suatu hal yang dicapai seseorang ketika berhasil melaksanakan pekerjaanya dengan sangat baik seperti tanggung jawab yang sudah diberikan perusahaan. Menurut Metin \& Asli (2018), kinerja merupakan bentuk realisasi dari pencapaian visi dan misi perusahaan dan bisa menjadi alat ukur untuk setiap individu, kelompok, maupun unit kerja agar bisa mencapai atau bahkan melebihi target produksi yang sudah ditetapkan sebelumnya. Andriyani \& Surjanti (2017) menyatakan gagasan kinerja merupakan kualitas dan kuantitas dari pekerjaan yang diselesaikan seseorang karyawan sesuai tanggung jawab yang telah diberikan dan sesuai standar perusahaan. Menurut Mendis \& Weerakkody (2017), kinerja karyawan adalah kemampuan karyawan untuk melakukan pekerjaan dengan cara tertentu yang mengarahkan ke organisasi dan karyawan untuk mencapai tujuan bersama.

Dari penjelasan pendapat beberapa ahli tersebut, kinerja karyawan ialah suatu pencapaian atas prestasi kerja, baik itu secara kualitas ataupun kuantitas yang telah dilakukan atas dasar tujuan pekerjaan yang dalam hal ini telah ditetapkan perusahaan (Rahman \& Kistyanto, 2019). Mengukur kinerja dari karyawan bisa dilakukan dengan mengetahui produktivitas karyawan secara kuantitas untuk membuat pekerjaan mereka di perusahaan menjadi lebih cepat selesai dan dengan kualitas yang sesuai standar perusahaan (Mpssoft.co.id, 2019).

Penelitian ini menggunakan indikator dari Mathis, R. L., \& Jackson (2008) karena fenomena yang terjadi di perusahaan sudah sesuai dengan indikator. Isi indikator ini ialah kuantitas akan hasil, kualitas akan hasil, ketepatan dalam mengerjakan tugas, serta absensi di tempat kerja.

\section{Hubungan antar Variabel}

Penelitian Obiageli et al. (2015) menyatakan work life balance dan kinerja memiliki hubungan positif. Menurut Mendis \& Weerakkody (2017) menyatakan bahwa work life balance berdampak signifikan dengan kinerja kerja dari karyawan. Bataineh (2019) menyatakan bahwa work life balanced menunjukkan hasil signifikan positif dan signifikan memengaruhi kinerja karyawan. Dan penelitian dari Mmakwe, Anthonia, \& Ukoha (2018), menyatakan bahwa ada korelasi positif yang kuat antara work life balanced dan kinerja karyawan.

H1: Diduga terdapat pengaruh positif work life balance pada kinerja karyawan PT. Bhinneka LifeIndonesia cabang Surabaya.

Berk \& Gundogmus (2018) membuktikan bahwa hubungan work life balance berdampak positif dengan komitmen karyawan terhadap organisasi. Azeem \& Akhtar (2014) memberikan bukti work life balance dengan komitmen karyawan memiliki hubungan positif. Duarte (2017) membuktikan bahwa work life balanced memberikan dampak positif terhadap komitmen dari karyawan di perusahaan. Sedangkan penelitian dari Kim (2014) menyatakan bahwa work life balanced mempunyai pengaruh signifikan positif terhadap kinerja karyawan di Korea. 
H2: Diduga terdapat pengaruh positif work life balance pada komitmen organisasi PT. Bhinneka Life Indonesia cabang Surabaya.

Martini, Rahyuda, Sintaasih, \& Piartrini (2018) mengatakan jika variabel komitmen afektif, variabel komitmen normative, dan variabel komitmen berkelanjutan memiliki dampak positif dengan variabel kinerja karyawan. Arifin et al. (2018) menyatakan adanya hubungan signifikan diantara komitmen karyawan pada organisasi dengan kinerja. Cesário \& Chambel (2017) memberikan pernyataan bahwa terdapat hubungan positif antara kinerja dari karyawan dengan komitmen yang menunjukkan hubungan kuat antar variabel. Sedangkan penelitian dari Sutanto \& Ratna (2015) menyatakan bahwa komitmen organisasi yang dimiliki seorang karyawan berpengaruh signifikan positif terhadap kinerja kerja mereka di perusahaan.

H3: Diduga terdapat pengaruh positif antara komitmen organisasi pada kinerja karyawan PT. Bhinneka Life Indonesia cabang Surabaya.

Menurut Gulbahar, Ch., Kundi, Qureshi, \& Akhtar (2014) work life balance mempunyai dampak signifikan dengan komitmen. Sementara Maulidiyah, Setyanti, \& Handriyono (2019) berkata variabel komitmen karyawan yang memiliki hubungan positif dengan variabel kinerja kerja mereka di perusahaan. Adapun penelitian lainnya oleh Pradhan, Jena, \& Kumari (2016) yang mengatakan bahwa analisis data yang menunjukkan komitmen organisasi dapat memediasi antara variabel dari work life balance serta variabel organizational citizenship behaviour.

H4: Diduga komitmen organisasi dapat menjadi mediasi hubungan antara work life balance pada kinerja karyawan PT. Bhinneka Life Indonesia cabang Surabaya.

\section{METODE PENELITIAN}

Jenis dari penelitian ini ialah penelitian kuantitatif. Lokasi yang diambil oleh penelitian ini ada di perusahaan asuransi PT. Bhinneka Life Indonesia cabang Surabaya. Penelitian ini memiliki populasi sebanyak 50 karyawan tetap pada seluruh bagian di PT. Bhinneka Life Indonesia cabang Surabaya dan sampel jenuh akan digunakan pada riset ini dalam pengumpulan sampel.

Beberapa variabel yang dipakai pada riset ini diantaranya variabel independen $(\mathrm{X})$, variabel dependen $(\mathrm{Y})$ dan variabel mediasi $(\mathrm{Z})$. Variabel bebas $(\mathrm{X})$ yaitu work life balance, variabel terikat $(\mathrm{Y})$ ialah kinerja karyawan dan variabel mediasi ialah komitmen organisasi.

Data yang terkumpul didapatkan dari observasi, wawancara dengan staf, serta penyebaran kuesioner. Menyebarkan kuesioner ke karyawan untuk diisi (data primer) setelah itu akan diperoleh hasil dari sumber-sumber lain yang menerbitkan (data sekunder) merupakan bentuk pengolahan sumber data di penelitian ini. Penelitian ini menggunakan teknik penghitungan dengan skala likert 1 sampai 5 di mana kategorinya antara lain sangat tidak setuju, tidak setuju, kurang setuju, setuju dan sangat setuju.

\section{HASIL DAN PEMBAHASAN}

\section{Hasil Validitas dan Reliabilitas}

Berdasarkan Tabel 1, terlihat bahwa semua outer loadings memiliki nilai di atas 0,70. Sehingga variabel-variabel di atas memiliki convergent validity yang baik. Selanjutnya, Tabel 2 menunjukkan nilai composite reliability dan cronbach's alpha untuk semua variabel lebih besar dari 0,70. Maka dengan demikian model variabel tersebut telah memenuhi composite reliability atau memiliki reliabilitas yang baik. 
Choirul Adam Ardiansyah \& Jun Surjanti. Pengaruh Work Life Balance terhadap Kinerja Karyawan melalui Komitmen Organisasi pada Karyawan PT. Bhinneka Life Indonesia Cabang Surabaya

Tabel 1.

OUTER LOADINGS VARIABEL

\begin{tabular}{lcc}
\hline Item & Outer Loadings & Keterangan \\
\hline X1.1 & 0,888 & Valid \\
X1.2 & 0,883 & Valid \\
Z1.1 & 0,785 & Valid \\
Z1.2 & 0,796 & Valid \\
Z1.3 & 0,826 & Valid \\
Y1.1 & 0,853 & Valid \\
Y1.2 & 0,792 & Valid \\
Y1.3 & 0,777 & Valid \\
Y1.4 & 0,811 & Valid \\
\hline
\end{tabular}

Sumber: Output Smart PLS 3.0

Tabel 2.

COMPOSITE RELIABILITY \& CRONBACH'S ALPHA VARIABEL

\begin{tabular}{lcc}
\hline \multicolumn{1}{c}{ Variabel } & Composite Realibility & Cronbach's Alpha \\
\hline Work Life Balance & 0,879 & 0,724 \\
Komitmen Organisasi & 0,844 & 0,723 \\
Kinerja Karyawan & 0,883 & 0,823 \\
\hline
\end{tabular}

Sumber: Output Smart PLS 3.0

\section{Hasil Uji Kausalitas}

Berdasarkan Tabel 3, terlihat bahwa ada nilai $t$-statistics pada Dirrect Effect dan Indirect Effect yang memiliki nilai kurang dari 1,96 pada pengaruh antara work life balanced terhadap kinerja karyawan. Selebihnya memiliki nilai di atas 1,96 atau hipotesis diterima.

Tabel 3.

DIRRECT EFFECT DAN INDERECT EFFECT

\begin{tabular}{|c|c|c|c|}
\hline Hubungan Antar Variabel & $\begin{array}{l}\text { Original } \\
\text { Sample }\end{array}$ & T-Statistics & Keterangan \\
\hline Work Life Balance $\rightarrow$ Komitmen Organisasi & 0,710 & 7,605 & $\begin{array}{l}\text { Hipotesis } \\
\text { Diterima }\end{array}$ \\
\hline Work Life Balance $\rightarrow$ Kinerja Karyawan & 0,078 & 0,813 & $\begin{array}{l}\text { Hipotesis Ditolak } \\
\text { Hipotesis }\end{array}$ \\
\hline $\begin{array}{l}\text { Komitmen Organisasi } \rightarrow \text { Kinerja Karyawan } \\
\text { Work Life Balance } \rightarrow \text { Komitmen Organisasi } \rightarrow \text { Kinerja } \\
\text { Karyawan }\end{array}$ & 0,805 & $\begin{array}{l}11,301 \\
5,515\end{array}$ & $\begin{array}{l}\text { Diterima } \\
\text { Hipotesis } \\
\text { Diterima }\end{array}$ \\
\hline
\end{tabular}

Sumber: Output Smart PLS 3.0

\section{Pengaruh Work Life Balance terhadap Kinerja Karyawan}

Hasil penelitian ini membuktikan bahwa variabel $W L B$ tidak berhubungan dengan variabel kinerja karyawan. Dari wawancara yang diadakan dengan karyawan, menyatakan bahwa karyawan seringkali lembur sehingga kurang ada waktu dengan keluarga, sebagian besar karyawan tetap dapat bekerja dengan baik, hal tersebut dikarenakan orientasi terhadap pemenuhan kebutuhan keluarga lebih penting dari segala hal, dan dengan menunjukkan kinerja yang semakin baik hal tersebut akan bisa tercapai. Sehingga $\mathrm{H} 1$ tidak terbukti.

Juga dapat diketahui dari nilai paling kecil salah satunya yaitu terdapat pada pernyataan yang menjelaskan dalam keseimbangan waktu yaitu karyawan dapat memenuhi kewajibannya terhadap keluarga dan lingkungan sekitar walaupun karyawan merasa kerepotan dalam hal mengatur waktu di tempat kerja. Hal ini berarti karyawan tetap sanggup memenuhi kewajiban yaitu pemenuhan 
kebutuhan keluarga secara materiil, walaupun terkadang harus sering pulang malam dan membuat pasangan merasa kurang ada waktu untuk menghabiskan momen kebersamaan dan banyak juga karyawan tidak ada waktu untuk menyalurkan hobi yang dimilikinya atau hanya ingin bertemu dengan teman di luar perusahaan, walapun demikian kinerja karyawan di perusahaan tetap baik bahkan cenderung naik.

\section{Pengaruh Work Life Balance terhadap Komitmen Organisasi}

Penelitian ini memberikan hasil adanya pengaruh $W L B$ dan komitmen karyawan. Hasil dari penelitian ini diperkuat pendapat penelitian lain dari Berk \& Gundogmus (2018) yang menyatakan WLB berdampak positif dengan komitmen organisasi. Sedangkan Arif, Bushra, Farooqi, \& Aftab (2014), menyatakan work life balance berdampak baik untuk meningkatkan komitmen dalam diri karyawan. Sedangkan penelitian dari Rene \& Wahyuni (2018) menyatakan WLB dan komitmen tidak memiliki hubungan dengan komitmen organisasi. Artinya, $\mathrm{H} 2$ terbukti.

Melalui hasil wawancara, karyawan merasa puas dalam bekerja saat atasan benar- benar mendukung ide-ide dan cara mereka dalam menyelesaikan suatu pekerjaan. Selain itu juga atasan memberikan arahan dalam hal tanggung jawab atas tugas yang diberikan saat terjadi banyak keperluan di luar yang harus selesai khususnya keluarga. Atasan juga memberikan kegiatan rutin mingguan bahkan bulanan untuk para karyawan agar tidak merasa bosan akan tuntutan pekerjaan yang semakin banyak. Cara ini dilakukan dengan cara olahraga secara rutin ataupun kegiatan social keluar untuk membantu sesama. Dengan cara itu karyawan menjadi pribadi yang professional dalam melaksanakan tugas karena tiap bulan akan selalu ada semangat baru dalam bekerja. Selain itu, atasan juga memberikan sebuah reward untuk para karyawan berhasil melebih target tiap bulannya maupun tiap tahunnya. Atasan juga menurut bapak imron juga sering mengadakan pelatihan baik tentang product knowledge maupun tentang hal-hal untuk meningkatkan produktivitas.

Dari analisis deskriptif responden menyatakan bahwa variabel work life balance mampu untuk meningkatkan komitmen para karyawannya, diantaranya dibuktikan melalui dukungan dari atasan yang memberikan kesempatan kepada karyawan untuk bertanggung jawab secara penuh untuk menyelesaikan pekerjaan tepat waktu di imbangi waktu yang diberikan atasan untuk berkumpul dengan keluarga dan kerabat mereka.

Juga dapat diketahui dari nilai paling kecil salah satunya yaitu terdapat pada pernyataan dalam indikator keseimbangan waktu yaitu diharapkan karyawan bisa menyelesaikan tanggung jawab kerja dan tanggung jawab di luar pekerjaan, seperti tanggung jawab di rumah ataupun di luar rumah. Berarti karyawan merasa tidak dapat membagi waktu antara keperluan keluarga dengan tugas di tempat kerja, karyawan tidak bisa menyelesaikan pekerjan dari perusahaan dengan waktu dan target yang ditentukan oleh perusahaan sebelumnya. Karena beberapa karyawan tidak memanfaatkan waktu itu sebaik mungkin untuk memaksimalkan pekerjaannya.

\section{Pengaruh Komitmen Organisasi terhadap Kinerja Karyawan}

Hasil penelitian membuktikan bahwa variabel komitmen memiliki hubungan dengan variabel kinerja karyawan. Penelitian ini diperkuat pendapat dari Arifin et al. (2018) yang mengatakan ada hubungan secara langsung diantara komitmen karyawan dengan kinerja. Dan penelitian dari Koskei, Kimutai, \& Bogonko (2018) menunjukkan bahwa ada hubungan negatif lemah diantara komitmen dengan kinerja karyawan. Dengan kata lain, H3 dapat dibuktikan.

Berdasarkan hasil wawancara, saat ini atasan sangat terbuka dalam hal mendengarkan keluhan para karyawan dan atasan dengan bijaksana tidak memaksakan kehendaknya, dibuktikan dengan mencari solusi terbaik untuk menunjang kehidupan karyawan serta kesejahteraan mereka bersama keluarga kecilnya. Atasan juga terbuka untuk diskusi akan kesulitan dalam melaksanakan pekerjaan, permasalahan saat bekerja. Atasan juga selalu memandang karyawan sebagai rekan kerja yang mempunyai tujuan sama mengembangkan perusahaan bukan sebagai anak buah perusahaan. Hal ini yang sering mengakibatkan para karyawan bekerja dengan sepenuh hati untuk organisasi ini. Dengan 
Choirul Adam Ardiansyah \& Jun Surjanti. Pengaruh Work Life Balance terhadap Kinerja Karyawan melalui Komitmen Organisasi pada Karyawan PT. Bhinneka Life Indonesia Cabang Surabaya

ini membuat karyawan cenderung puas dengan keadaan yang ada dalam lingkungan pekerjaannya sehingga tidak menghambat kinerjanya dalam mencapai target yang ditetapkan perusahaan.

Dari analisis deskriptif responden menyatakan bahwa variabel komitmen organisasi mampu untuk mengarahkan para karyawannya dalam meningkatkan kinerjanya dengan rasa puas terhadap pekerjaan itu sendiri, dari perlakuan atasan kepada para karyawan, dari hasil gaji/upah/bonus yang diterima yaitu saat karyawan berprestasi dalam hal melebihi target penjualan asuransi yang sudah ditentukan oleh perusahaan sebelumnya. Juga dapat diketahui nilai paling kecil terdapat dalam indikator komitmen berkelanjutan, yang ada pada pernyataan adanya perasaan karyawan untuk tetap tinggal di perusahaan karena ini merupakan keinginan mereka sendiri.

Berdasarkan hal tersebut berarti karyawan merasa bahwa dirinya belum sepenuhnya memiliki keinginan untuk tetap tinggal di perusahaan ini, sehingga perusahaan memerlukan kebijakan pengembangan karir, atasan yang lebih terbuka akan masalah yang dihadapi oleh para karyawan, serta bonus ketika karyawan melebihi target yang di tentukan oleh perusahaan, karena saat ini perusahaan masih belum menerapkan mengenai kebijakan tersebut secara baik, kebijakan itu umumnya didasarkan atas prestasi, kompetensi kerja, dan karyawan baru yang telah memenuhi syarat di perusahaan, hal ini diharapkan memiliki dampak pada peningkatan kinerja.

Hal ini sama dengan penelitian Cesário \& Chambel (2017) bahwa perusahaan harus berusaha meningkatkan komitmen organisasi karyawan karena secara tidak langsung hal tersebut memicu adanya pemikiran tentang bekerja sepenuh hati pada organisasi sehingga akan menghasilkan peningkatan kinerja karyawan. Penelitian Arifin et al. (2018) mengatakan perusahaan yang memetingkan komitmen kepada organisasinya akan memiliki dampak yang signifikan terhadap kinerja dari karyawan. Sedangkan penelitian dari Sutanto \& Ratna (2015) mendeskripsikan bahwa kinerja dapat meningkat ketika komitmen kerja dari karyawan di perusahaan juga meningkat. Artinya, secara statistik dan hasil wawancara dapat diketahui jika variabel komitmen memiliki hubungan dengan variabel kinerja, di mana semakin tinggi intensitas komitmen karyawan ketika bekerja maka dampaknya akan memicu kinerja karyawan yang semakin meningkat.

\section{Pengaruh Work Life Balance terhadap Kinerja Karyawan melalui Komitmen Organisasi}

Variabel work life balance tidak berdampak langsung dengan variabel kinerja, dan memengaruhi secara tidak langsung variabel kinerja melalui bantuan lewat variabel komitmen organisasi. Penelitian ini diperkuat dengan penelitian dari Kim (2014), variabel work life balance berhubungan dengan variabel kinerja karyawan secara tidak langsung. Sedangkan variabel work life balance dapat meningkatkan variabel komitmen afektif. Serta komitmen afektif berdampak signifikan dengan kinerja. Penelitian ini memberikan hasil jika variabel komitmen afektif bisa menjadi mediasi hubungan antara variabel work life balance dengan variabel kinerja. Menggunakan variabel work life balance, variabel kinerja, serta komitmen afektif atau dengan kata lain $\mathrm{H} 4$ diterima.

Hasil wawancara menunjukkan bahwa semakin bertahap karyawan telah mempunyai komitmen dalam bekerja, baik dalam hal pekerjaan itu sendiri, bimbingan dari atasan untuk masalah yang mereka hadapi, gaji/bonus yang diberikan perusahaan ketika melebihi target, bersikap professional saat bekerja meskipun banyak permasalahan di luar pekerjaan, dan dukungan dari rekan kerja yang ada di perusahaan. Karyawan mempunyai kepercayaan diri untuk menyelesaikan pekerjaan yang diberikan oleh perusahaan mereka tepat waktu, dapat menyumbangkan ide kreatif untuk kemajuan dari perusahaan, dan mencoba hal baru yang berfungsi untuk perkembangan perusahaan, yang salah satu faktornya disebabkan dari persepsi karyawan atas kondisi organisasi yang semakin baik dalam lingkungan PT. Bhinneka Life Indonesia cabang Surabaya, sehingga komitmen yang telah dimiliki karyawan atas kondisi organisasi tersebut akan berdampak terhadap kinerja dari setiap diri karyawan. Hal tersebut dapat memberi informasi bahwa variabel komitmen karyawan terhadap pekerjaan yang dirasakan akan berdampak signifikan positif diantara hubungan work life balance dan kinerja. 


\section{KESIMPULAN}

Dari hasil penelitian di atas, maka dapat disimpulkan bahwa: pertama, pada hasil riset menjelaskan variabel work life balance dan variabel kinerja tidak memiliki hubungan. Meskipun PT. Bhinneka Life Indonesia cabang Surabaya telah menerapkan work life balance dengan baik dan kondusif, tetapi belum bisa memberikan dampak terhadap peningkatan variabel kinerja kerja para karyawan; kedua, work life balance berdampak positif dengan komitmen karyawan. Berarti karyawan yang berada di PT. Bhinneka Life Indonesia cabang Surabaya mampu menerapankan work life balance dengan baik dan berdampak pada komitmen organisasi karyawan; ketiga, komitmen dan kinerja karyawan memiliki hubungan siginifikan. Karyawan PT. Bhinneka Life Indonesia cabang Surabaya memiliki komitmen kuat terhadap organisasi, jadi dapat menimbulkan peningkatan pada kinerja; keempat, work life balance berdampak signifikan terhadap kinerja melalui komitmen karyawan. Disimpulkan jika komitmen organisasi yang ada di perusahaan dapat menjadi subyek mediasi antara variabel work life balance dengan variabel kinerja. Tetapi hubungan variabel work life balance dan variabel kinerja memiliki nilai tidak signifikan (nilai signifikansi kurang dari standar).

Adapun saran yang diberikan oleh penelian ini di antaranya sebagai berikut. Pertama, sebaiknya atasan lebih memperhatikan akan kebutuhan work life balance karyawannya di kantor. Kedua, perusahaan harus tetap memperhatikan apa yang menjadi kebutuhan karyawannya agar komitmen para karyawan untuk organisasi lebih baik. Ketiga, perusahaan memberikan pelatihan lagi untuk para karyawan agar bisa meningkatkan hasil kualitas dari pekerjaan mereka. Penelitian selanjutnya dapat melibatkan budaya organisasi. Penerapan work life balance di perusahaan juga tidak berjalan konsisten sesuai dengan apa yang diharapkan sebelumnya. Hal ini yang mengakibatkan hubungan antara work life balance dengan kinerja karyawan di perusahaan tidak berpengaruh.

\section{DAFTAR PUSTAKA}

Andini, I., \& Surjanti, J. (2017). Pengaruh Work-Life Balance dan Komitmen Afektif Terhadap Kepuasan Karir Pada PT. Sinar Karya Duta Abadi. Jurnal Ilmu Manajemen, 5(3), 1-10.

Arif, Bushra, Farooqi, \& Aftab, Y. (2014). Impact of Work Life Balance on Job Satisfaction and Organizational Commitment Among University Teachers: A Case Study of University of Gujrat, Pakistan. International Journal Of Multidisciplinary Sciences and Engineering, 5(9).

Arifin, Z., Rivai, A., \& Sodikin, A. (2018). The Effect of Organizational Commitment and Integrity on Employee Performance through Motivation PT . Parsariran. IOSR Journal of Business and Management (IOSR-JBM), 20(7), 23-32. https://doi.org/10.9790/487X-2007052332

Azeem, S. M., \& Akhtar, N. (2014). The Influence of Work Life Balance and Job Satisfaction on Organizational Commitment of Healthcare Employees. International Journal of Human Resource Studies, 4(2), 18-24. https://doi.org/10.5296/ijhrs.v4i2.5667

Bataineh, K. Adnan. (2019). Impact of Work-Life Balance, Happiness at Work, on Employee Performance. International Business Research, 12(2), 99-112. https://doi.org/10.5539/ibr.v12n2p99

Berk, C., \& Gundogmus, F. (2018). The Effect of Work-Life Balance on Organizational Commitment of Accountants. Management, 13(2), 137-159.

Cesário, F., \& Chambel, M. J. (2017). Linking Organizational Commitment and Work Engagement to Employee Performance. Knowledge and Process Management, 1-7. https://doi.org/10.1002/kpm.1542

Djajendra. 2013. Work Life Balance Menciptakan Etos Kerja yang Unggul. 
Choirul Adam Ardiansyah \& Jun Surjanti. Pengaruh Work Life Balance terhadap Kinerja Karyawan melalui Komitmen Organisasi pada Karyawan PT. Bhinneka Life Indonesia Cabang Surabaya

https://www.kompasiana.com/djajendra.com/5528b238f17e61b3798b456f/work-life-balancemenciptakan-etos-kerja-yang-unggul, diakses pada 19 Juli 2020

Duarte, I. P. (2017). Affective Commitment to Change and Work-Life Balance: Mediating Factors. Campus de Campolide.

Gulbahar, Ch., A. A., Kundi, G. M., Qureshi, Q. A., \& Akhtar, R. (2014). Relationship between Work-Life Balance \& Organizational Commitment. Research on Humanities and Social Sciences, 4(5), 1-7.

Ilham, Mughfinar. 2020. Pengertian Komitmen Organisasi, Manfaat, Bentuk, Indikator dan Faktor. https://materibelajar.co.id/pengertian-komitmen-organisasi/, diakses pada 8 Juli 2020

Kim, H. K. (2014). Work- Life Balance and Employees ' Performance: The Mediating Role of Affective Commitment. Global Business and Management Research: An International Journal, $6(1), 37-51$.

Kithae, D. P. P., \& Keino, D. C. (2016). Effects of Work Life Balance on Staff Performance in the Telecommunication Sector in Kenya. Archives of Business Research, 4(1), 129-138.

Koskei, T. A. H., Kimutai, G., \& Bogonko, J. (2018). Continuance Commitment and Employee Performance at University of Eastern Africa , Baraton Kenya. IOSR Journal of Business and Management (IOSR-JBM), 20(2), 61-67. https://doi.org/10.9790/487X-2002056167

Langford, P. H. (2009). Measuring organisational climate and employee engagement: Evidance: For a 7 Ps model of work prctices and outcomes. Australian Journal of Psychology, 61(4), 185-198.

Martini, I. A. O., Rahyuda, I. K., Sintaasih, D. K., \& Piartrini, P. S. (2018). The Influence of Competency on Employee Performance through Organizational Commitment Dimension. IOSR Journal of Business and Management (IOSR-JBM), 20(2), 29-37. https://doi.org/10.9790/487X-2002082937

Maulidiyah, N. N., Setyanti, S. W. L. H., \& Handriyono. (2019). The Role of Organizational Commitment In Mediating The Influence of Work Family Conflict and Job Stress On Employee Performance. Ijciras, 1(12), 1-6.

Mendis, M. D. V. S., \& Weerakkody, W. A. S. (2017). The Impact of Work Life Balance on Employee Performance with Reference to Telecommunication Industry in Sri Lanka: A Mediation Model. Kelaniya Journal of Human Resource Management, 12(1), 72-100.

Metin, K., \& Asli, K. (2018). The Relationship between Organizational Commitment and Work Performance : a Case of Industrial Enterprises. Journal of Economic and Social Development (JESD), 5(1), 46-50.

Mmakwe, Anthonia, K., \& Ukoha, O. (2018). Work-Life Balance and Employee Performance In Nigerian Banks, Port Harcourt. International Journal of Advanced Academic Research, 4(1), $107-119$.

Mpssoft.co.id 2019. Mengukur Kinerja Karyawan dengan 5 Metode Akurat. http://www.mpssoft.co.id/blog/hrd/mengukur-kinerja-karyawan-dengan-5-metode-akurat/, diakses pada 18 Juli 2020

Nugraha, Toni. 2016. Loyalitas dan Komitmen Kerja Serja Seorang Pegawai. https://sites.google.com/site/bbppbinuang/artikel-1/loyalitasdankomitmenkerjaseorangpegawai, diakses pada 25 Juni 2020. 
Obiageli, O. L., Uzochukwu, O. C., \& Ngozi, C. D. (2015). Work life balance and employee performance in selected commercial banks in lagos state. European Journal Research and Reflection in Management Sciences, 3(4), 63-77.

Pradhan, R. K., Jena, L. K., \& Kumari, I. G. (2016). Effect of Work-Life Balance on Organizational Citizenship Behaviour : Role of Organizational Commitment. Global Business Review, 17(3S), 1-16. https://doi.org/10.1177/0972150916631071

Rahman, M. F. W., \& Kistyanto, A. (2019). Hubungan Antara Iklim Psikologis Terhadap Kinerja Karyawan Melalui Kepuasan Kerja. Dinamika Ekonomi Jurnal Ekonomi Dan Bisnis, 12(2), 410-429.

Rene, R., \& Wahyuni, S. (2018). Pengaruh Work-Life Balance Terhadap Komitmen Organisasi, Kepuasan Kerja , dan Motivasi Kerja Terhadap Kinerja Individu Pada Karyawan Perusahaan Asuransi Di Jakarta. Jurnal Manajemen Dan Bisnis Sriwijaya, 16(1), 1-11.

Republik Indonesia. 2016. Peraturan Otoritas Jasa Keuangan Nomor 67 tentang Perizinan Usaha dan Kelembagaan Perusahaan Asuransi, Perusahaan Asuransi Syariah, Perusahaan Reasuransi, dan Perusahaan Reasuransi Syariah. Otoritas Jasa Keuangan. Jakarta.

Sari, Usnawati Indria. 2015. Pentingnya Komitmen Karyawan Bagi Organisasi. https://www.kompasiana.com/usnawatiindria/54f96055a3331169018b4e54/pentingnyakomitmen-karyawan-bagiorganisasi\#: : :text=Komitmen\%20yang\%20tinggi\%20akan\%20memacu,yang\%20sesuai\%20den gan\%20yang\%20diharapkan., diakses pada 18 Juli 2020

Sutanto, E. M., \& Ratna, A. (2015). Pengaruh Komitmen Organisasional Terhadap Kinerja Karyawan Berdasarkan Karakteristik Individual. Jurnal Bisnis Dan Manajemen, 9(1), 56-70. 